\section{Healthy China 2030: a missed opportunity for injury control}

\author{
Peishan Ning, ${ }^{1}$ David C Schwebel, ${ }^{2}$ Guoqing $\mathrm{Hu}^{1}$
}

On 25 October 2016, the Central Committee of the Communist Party of China and the State Council of China released the Healthy China 2030 blueprint guide. ${ }^{1}$ For the first time, a longterm national health initiative includes injury control, as it specifies actions to improve occupational safety, road traffic safety and injury prevention. However, the blueprint misses a fundamental priority for injury control-no specific department or agency is assigned to lead and coordinate the efforts of the multiple departments and social partners working to prevent injuries in China. ${ }^{2} 3$

The absence of such a lead agency will seriously impede the development of injury control in China. Most prominently, a top-down professional team is not responsible for injury control, which can compromise nationwide implementation and the use of evidence-based, affordable and easy-to-implement interventions that are used in other nations. The lack of a centralised agency responsible for injury control also affects national investment in injury research. As seen in the national health research agendas of China over the past three decades, injury prevention research is excluded from priority listings of recently released national long-term scientific grant announcements (http:// www.most.gov.cn) and the 13th 5-year plan of the National Natural Science Foundation of China (http://www.nsfc.gov. cn/nsfc/cen/bzgh_135/index.html).

This situation is particularly concerning because injuries represent a significant threat to the health of the Chinese people. According to Global Burden of Diseases 2015 estimates, ${ }^{4}$ injuries cause more than $40 \%$ of total deaths among individuals aged 1-34 years in China (figure 1).

\footnotetext{
${ }^{1}$ Department of Epidemiology and Health Statistics, Xiangya School of Public Health, Central South University, Changsha, Hunan, China; ${ }^{2}$ Department of Psychology, University of Alabama at Birmingham, Birmingham, Alabama, USA

Correspondence to Dr Guoqing Hu, Department of Epidemiology and Health Statistics, Xiangya School of Public Health, Central South University, 110 Xiangya Road, Changsha, Hunan 410078, China; huguoqing009@gmail.com
} (China, 2015).
Transport injuries, which are dominated by road traffic crashes, are the leading cause of injury deaths for most age groups in China.

To achieve the ultimate goal of Healthy China 2030-to 'promote the health of the Chinese'-the overlooked priority of injury prevention and control must be urgently addressed. The success of the USA in establishing the National Center for Injury Prevention and Control at the CDC offers an excellent model. ${ }^{5}$ The Chinese government should assign a single agency to lead national injury control efforts and coordinate the existing work of various departments, social organisations and agencies, industry and the public as soon as possible. Strategic planning and implementation could occur under the leadership of such an agency, ultimately offering a long-term national agenda that prioritises and implements surveillance, prevention, treatment, rehabilitation and research efforts for injury control.

Contributors We declare that all the authors completed the design, interpretation and writing, and that we have seen and approved the final version.

Competing interests None declared.

Provenance and peer review Not commissioned; internally peer reviewed.
Open Access This is an Open Access article distributed in accordance with the Creative Commons Attribution Non Commercial (CC BY-NC 4.0) license, which permits others to distribute, remix, adapt, build upon this work non-commercially, and license their derivative works on different terms, provided the original work is properly cited and the use is non-commercial. See: http:/l creativecommons.org/licenses/by-nc/4.0/

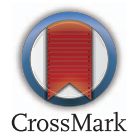

To cite Ning P, Schwebel DC, Hu G. Inj Prev 2017;23:363.

Received 3 January 2017

Accepted 18 January 2017

Published Online First 23 February 2017

Inj Prev 2017;23:363.

doi:10.1136/injuryprev-2017-042314

\section{REFERENCES}

1 The Central Committee of the Communist Party of China and the State Council of China. Blueprint of Healthy China 2030. News (Xinhua Net). October 25, 2016. http://news.xinhuanet.com/health/2016-10/25/ c_1119786029.htm (accessed 26 Oct 2016).

2 Hu G, Baker TD, Li G, et al. Injury control: an opportunity for China. Inj Prev 2008;14:129-30.

3 Hu G, Baker TD, Baker SP. Injury control in China: priorities and actions. Lancet 2009;373:214.

4 Institute for Health Metrics and Evaluation, University of Washington. GBD Compare|Viz Hub (cited 1 November 2016). http://vizhub.healthdata.org/gbd-compare/

5 Sleet DA, Baldwin G, Marr A, et al. History of injury and violence as public health problems and emergence of The National Center for Injury Prevention and Control at CDC. I Safety Res 2012;43:233-47.

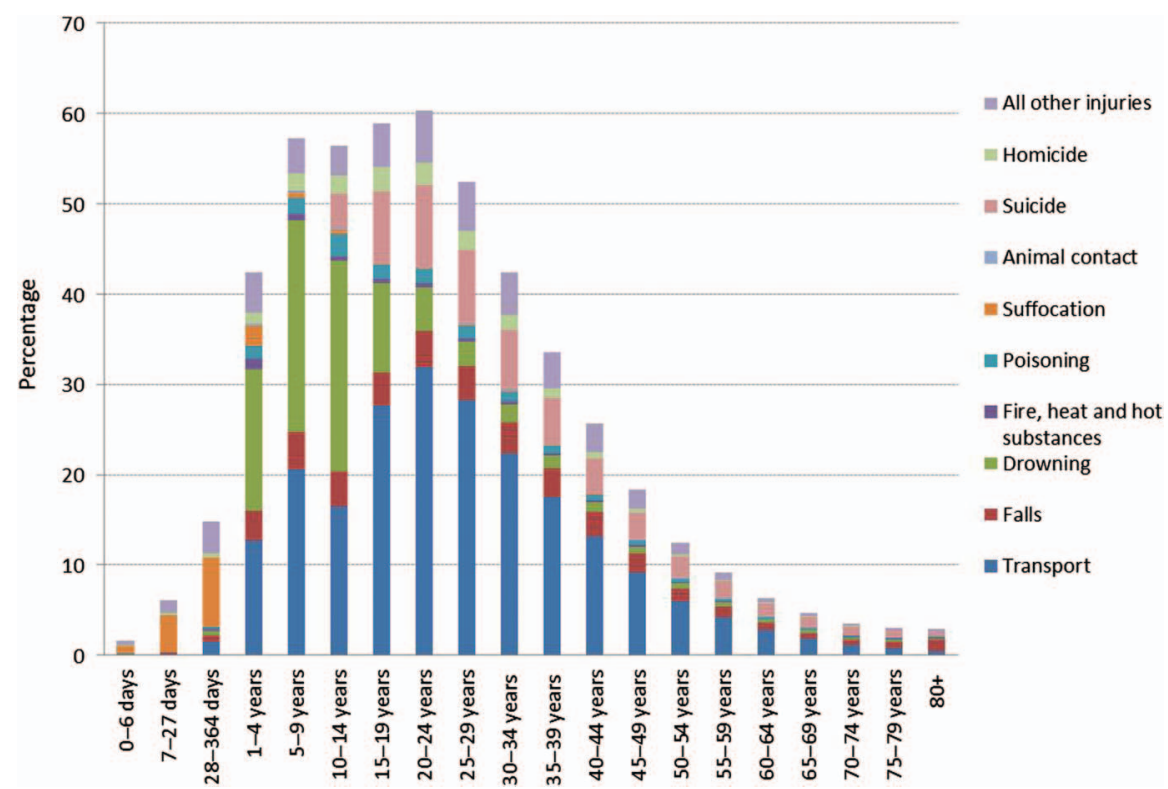

Figure 1 Percentage of deaths from specific injury causes among all deaths by age group 